\title{
The occurrence of Blumeriella jaapii resistant forms to dodine and benzimidazole fungicides in selected orchards in central Poland
}

\section{Występowanie form odpornych grzyba Blumeriella jaapii na fungicydy dodynowe i benzimidazolowe w wybranych sadach Polski centralnej}

\author{
Paulina Seliga, Agata Broniarek-Niemiec*, Anna Poniatowska, Monika Michalecka
}

\begin{abstract}
Summary
Cherry leaf spot (Blumeriella jaapii) is the most dangerous disease of orchards and nurseries of stone fruit trees, especially sour cherries. Chemical method is the primary tool for controlling cherry leaf spot. Dodine, benzimidazole and triazole fungicides are the most commonly used. The frequent application of these fungicide groups resulted in the development of resistant forms of the causal agent to their active substances. In years 2012-2015 in 33 selected sour cherry orchards located in central Poland, the occurrence of resistant forms of $B$. jaapii to dodine and benzimidazoles was determined by using a spore germination test on the poisoned agar medium. The study showed high resistance to thiophanate-methyl in 15 orchards, and to dodine in 5 orchards. The medium resistance to thiophanate-methyl and dodine occurred in 7 orchards. Low level of resistant forms to thiophanate-methyl was found in 11 orchards, and to dodine - in 21 . The obtained results will be the basis for implementation of cherry leaf spot control programs in regard to appropriate antiresistance guidelines.
\end{abstract}

Key words: leaf spot; resistance to fungicides; thiophanate-methyl; dodine

\section{Streszczenie}

Drobna plamistość liści drzew pestkowych (Blumeriella jaapii) jest najgroźniejszą chorobą sadów i szkółek drzew pestkowych, zwłaszcza wiśni. W jej zwalczaniu najważniejszą rolę odgrywa metoda chemiczna. Najczęściej stosowane są fungicydy dodynowe, benzimidazolowe i triazolowe. Wielokrotne stosowanie tych grup fungicydów skutkuje pojawianiem się form odpornych sprawcy choroby na ich substancje czynne. W latach 2012-2015 w 33 wybranych sadach wiśniowych położonych w Polsce centralnej, oceniano za pomocą testu kiełkowania zarodników na zatrutej pożywce agarowej, występowanie form odpornych $B$. jaapii na preparaty dodynowe oraz benzimidazolowe. Przeprowadzone badania wykazały wysoką odporność na tiofanat metylu w 15 sadach, a na dodynę w 5 sadach. Średnia odporność na tiofanat metylu i dodynę wystąpiła w 7 sadach. Niski poziom form odpornych na tiofanat metylu stwierdzono w 11 sadach, a na dodynę - w 21. Uzyskane wyniki będą podstawą do wprowadzania odpowiednich założeń antyodpornościowych w opracowywanych programach zwalczania drobnej plamistości liści drzew pestkowych.

Słowa kluczowe: drobna plamistość liści drzew pestkowych; odporność na fungicydy; tiofanat metylu; dodyna

\footnotetext{
Instytut Ogrodnictwa

Pracownia Fitopatologii Sadowniczej

Pomologiczna 18, 96-100 Skierniewice

*corresponding author: agata.broniarek@inhort.pl
} 


\section{Wstęp / Introduction}

Drobna plamistość liści drzew pestkowych (Blumeriella jaapii) jest najgroźniejszą chorobą sadów i szkółek drzew pestkowych, zwłaszcza wiśni (Prunus cerasus), we wszystkich rejonach jej uprawy (Broniarek-Niemiec i Bielenin 2008; Holb i wsp. 2010, 2014; Broniarek-Niemiec i wsp. 2013). Przy silnym porażeniu liści dochodzi do częściowej lub całkowitej defoliacji drzew, co skutkuje pogorszeniem jakości owoców (owoce nie dojrzewają), a zawiązujące się pąki kwiatowe są nieodżywione, co wpływa negatywnie na plonowanie w kolejnym sezonie oraz obniża wytrzymałość roślin na mróz (Diaz i wsp. 2007; Grzyb i wsp. 2012). Nasilenie choroby zależy od podatności uprawianej odmiany (powszechnie uprawiana w Polsce odmiana wiśni Łutówka jest najbardziej podatna), warunków atmosferycznych oraz wielkości pierwotnego źródła infekcji (Broniarek-Niemiec i Bielenin 2008; Holb i wsp. 2010, 2014; Broniarek-Niemiec i wsp. 2013). W zwalczaniu drobnej plamistości liści drzew pestkowych najważniejszą rolę odgrywa metoda chemiczna. W warunkach klimatycznych Polski przeciwko chorobie, zwykle wykonuje się od 4 do 6 zabiegów w sezonie. Najczęściej stosowane są środki dodynowe, benzimidazolowe (tiofanat metylu) i triazolowe (Broniarek-Niemiec i Bielenin 2008; Broniarek-Niemiec i wsp. 2013; Program Ochrony Roślin Sadowniczych 2015).

Według Międzynarodowego Komitetu Badań nad Odpornością na Fungicydy (FRAC - Fungicide Resistance Action Committee) benzimidazole zalicza się do grupy związków o wysokim ryzyku powstawania odporności, gdyż ich mechanizm działania jest wysoce specyficzny. Związki te wiążą się $\mathrm{z}$ podjednostką beta białek tubulinowych grzybów, ograniczając w ten sposób kurczliwość mikrotubul wrzeciona kariokinetycznego, przez co zahamowany zostaje proces mitotycznego podziału jądra. Duża zmienność genetyczna grzybów, w tym także B. jaapii, sprzyja jednak jednopunktowym mutacjom w obrębie genu $\beta$-tubuliny. Mutacje te powodują zmiany w sekwencji aminokwasów białka $\beta$-tubuliny grzybów, wpływając na obniżenie wiązania przez to białko substancji czynnych fungicydów bezimidazolowych (Ma i Michailides 2005; Nowaczyk i Obrępalska-Stęplowska 2006).

Mechanizm działania fungicydów dodynowych nie jest do końca poznany. Polega on między innymi na zakłócaniu funkcjonowania błony cytoplazmatycznej komórek grzyba, w wyniku czego traci ona swoje półprzepuszczalne właściwości i następuje niekontrolowany wypływ istotnych dla grzyba metabolitów oraz wody. Brak tych substancji powoduje zahamowanie różnych procesów fizjologicznych i w konsekwencji prowadzi do śmierci patogena (Kryczyński 2002). Jest to mechanizm mało specyficzny, a ryzyko powstania odporności grzybów na te fungicydy określane jest jako średnie. Formy odporne grzybów na fungicydy dodynowe pojawiają się zazwyczaj dopiero po kilkudziesięciu latach intensywnego stosowania tych związków w sadzie (Jones 1981; Holb i wsp. 2010).

Celem badań było określenie przy użyciu testu kiełkowania zarodników występowania form odpornych grzyba $B$. jaapii na fungicydy dodynowe $\mathrm{i}$ benzimidazolowe w wybranych sadach wiśniowych i czereśniowych zlokalizowanych w Polsce centralnej.

\section{Materiały i metody / Materials and methods}

Badania nad występowaniem form odpornych $B$. jaapii na fungicydy dodynowe oraz benzimidazolowe przeprowadzono w latach 2012-2015 w 33 sadach wiśniowych, położonych w województwie łódzkim i mazowieckim. Na przełomie lipca i sierpnia, z każdego sadu z kilku losowo wybranych drzew, pobierano próby 20 liści z objawami drobnej plamistości liści drzew pestkowych. Po przewiezieniu do laboratorium z każdego liścia wycinano sterylnym skalpelem małe fragmenty tkanki z zarodnikującymi owocnikami grzyba i zawieszano je w $1 \mathrm{ml}$ sterylnej wody dejonizowanej $\mathrm{z}$ dodatkiem mieszaniny antybiotyków: $50 \mu \mathrm{g} / \mathrm{ml}$ ampicyliny, $520 \mu \mathrm{g} / \mathrm{ml}$ streptomycyny i $200 \mu \mathrm{g} / \mathrm{ml}$ chloramfenikolu. Tak przygotowaną zawiesinę, zawierającą mieszaninę zarodników z wszystkich 20 liści, nanoszono na agarową pożywkę ziemniaczano-dekstrozową (PDA - Potato Dextrose Agar) z dodatkiem odpowiedniego fungicydu oraz na pożywkę kontrolną - bez fungicydu. W testach przeprowadzonych w 2012 roku tiofanat metylu (związek z grupy benzimidazoli) i dodynę zastosowano w stężeniach: 1, 10 i 100 ppm, a w latach 2013-2015 tiofanat metylu zastosowano w stężeniach: 10, 50 i 100 ppm, a dodynę - 1 ppm. Po 24 godzinach inkubacji w temperaturze pokojowej w każdym $\mathrm{z}$ dziesięciu pól obserwacyjnych przeprowadzano ocenę kiełkowania 100 zarodników przy użyciu mikroskopu optycznego przy powiększeniu 100x. Indeks kiełkujących zarodników (IKZ) obliczono według wzoru opracowanego we wcześniejszych badaniach nad odpornością grzyba Venturia inaequalis - sprawcy parcha jabłoni na fungicydy dodynowe i strobilurynowe (Broniarek-Niemiec i Bielenin 2005)

\section{$\mathrm{IKZ}[\%]=$}

Liczba kiełkujących zarodników na podłożu z dodatkiem fungicydu x 100\% Liczba kiełkujących zarodników na podłożu bez dodatku fungicydu

W zależności od wartości obliczonego indeksu (IKZ) przyjęto trzy poziomy odporności: niska odporność IKZ $<20 \%$, średnia $-20 \%<$ IKZ $<50 \%$ i wysoka IKZ $>$ $50 \%$.

\section{Wyniki i dyskusja / Results and discussion}

Badania przeprowadzone w 2012 roku z próbami pochodzącymi z 11 sadów wiśniowych wykazały istotne różnice w kiełkowaniu zarodników $B$. jaapii już przy stężeniu $10 \mathrm{ppm}$ tiofanatu metylu. Przy takim stężeniu w 7 sadach stwierdzono ponad 90\% kiełkujących zarodników, co świadczy o wysokim stopniu odporności badanych populacji grzyba na ten związek. W pozostałych sadach odsetek kiełkujących zarodników wyniósł od 0 do $25,6 \%$, co wskazuje na wyższą wrażliwość patogena na tiofanat metylu w tych populacjach. Przy stężeniu $1 \mathrm{ppm}$ tiofanatu metylu w większości analizowanych prób nie stwierdzono natomiast istotnych różnic w kiełkowaniu zarodników (oprócz sadu w Dębowej Górze), a przy stężeniu 100 ppm tylko w próbach z 3 sadów stwierdzono kiełkujące zarodniki na poziomie od 6,5 do $33 \%$. 
Istotne zróżnicowanie $\mathrm{w}$ kiełkowaniu zarodników na pożywce $\mathrm{z}$ dodatkiem dodyny zaobserwowano natomiast już przy stężeniu 1 ppm. W takich warunkach, w próbach z 7 sadów kiełkowanie zarodników grzyba B. jaapii wahało się od 18,2 do $58,6 \%$, a w próbach $\mathrm{z}$ pozostałych sadów było ono całkowicie zahamowane. Przy stężeniu dodyny 10 i 100 ppm w żadnej próbie nie stwierdzono kiełkowania zarodników (tab. 1).

$\mathrm{Na}$ podstawie wyników testów przeprowadzonych w 2012 roku, w kolejnych latach badań (2013-2015), wybrano tylko te stężenia fungicydów, które istotnie różnicowały populacje grzyba.

W 2013 roku badaniami objęto 13 kolejnych sadów. Przeprowadzone testy wykazały, że przy stężeniu 10 ppm tiofanatu metylu, we wszystkich próbach, kiełkowanie zarodników wyniosło od 46 do 100\%. Znacznie większe zróżnicowanie uzyskano natomiast przy stężeniu 50 ppm. W próbach pochodzących z 6 sadów indeks kiełkujących zarodników wyniósł ponad 52\%, z 5 sadów - od 20,8 do $48,2 \%$, a w pozostałych - 0,6 i 11,8\%. Przyjmując opisane powyżej poziomy odporności można stwierdzić, że wśród 13 badanych sadów w 6 występowała wysoka odporność na tiofanat metylu, w 5 - średnia, a w 2 sadach formy odporne były na niskim poziomie. Stężenie 100 ppm spowodowało znaczne zahamowanie kiełkowania. Indeks kiełkujących zarodników wahał się od 0,6 do 54,9\%.

Badania odporności $B$. jaapii na dodynę wykazały w 11 sadach niski poziom odporności (od 0 do 15,7\% kiełkujących zarodników), a w 2 - średni (IKZ 43,7 i 49,7\%) (tab. 2).

Analiza przeprowadzona w 2014 roku z próbami pobranymi z 5 sadów wykazała, że przy stężeniu 50 ppm tiofanatu metylu, w 2 sadach występował wysoki poziom odporności (57,8 i 62,2\% kiełkujących zarodników), a w 3 sadach populacja grzyba była wrażliwa na zastosowany środek (IKZ od 7,7 do 10,0\%).

$\mathrm{Na}$ pożywce $\mathrm{z}$ dodyną wysoki indeks kiełkujących zarodników (powyżej 72\%) stwierdzono w 4 analizowa- nych próbach, a w jednej próbie kiełkowanie zarodników było niższe i wyniosło $39,3 \%$, co oznacza średni poziom odporności na dodynę (tab. 3).

W 2015 roku ze względu na niekorzystne dla rozwoju patogena warunki atmosferyczne (wysoka temperatura, brak opadów) drobna plamistość liści drzew pestkowych w sadach wiśniowych wystąpiła w bardzo niskim nasileniu. Przeprowadzone testy na pożywce PDA z dodatkiem fungicydów wykazały, że zarodniki grzyba uzyskane z pobranych prób były wrażliwe na dodynę oraz tiofanat metylu (tab. 4).

Podsumowując można stwierdzić, że wśród 33 sadów wiśniowych wysoka odporność grzyba $B$. jaapii na tiofanat metylu występowała w 15 sadach, średnia - w 7, a niska w 11. Wysoką odporność na dodynę stwierdzono natomiast w 5 sadach, średnią - w 7, a niską - w 21 badanych sadach.

Problem nabywania odporności przez patogeny grzybowe na stosowane środki ochrony roślin obserwowany jest od kilkudziesięciu lat w wielu krajach na świecie (Proffer i wsp. 2006; McManus i wsp. 2007). W dużej mierze wynika on $\mathrm{z}$ faktu, że większość substancji grzybobójczych nowej generacji charakteryzuje się selektywnym mechanizmem działania, polegającym na zakłóceniu wybranych, ściśle określonych procesów fizjologicznych patogena.

Odporność na fungicydy dodynowe i benzimidazolowe stwierdzono między innymi u $V$. inaequalis - sprawcy parcha jabłoni (Nowacka i wsp. 1977; Jones 1981; Nowacka 1991; Köller i Wilcox 2001; Meszka i wsp. 2011; Broniarek-Niemiec i wsp. 2012). Pierwsze doniesienia o pojawieniu się odporności grzyba $B$. jaapii na fungicydy dodynowe odnotowano w stanie Michigan w USA w latach 80. ubiegłego wieku, a więc dopiero po około 30 latach ich stosowania (Holb i wsp. 2010). Wystąpienie odporności na benzimidazole nastąpiło znacznie szybciej, bo już po 3-5 latach od ich wprowadzenia na rynek amerykański (Jones i Ehret 1980).

Tabela 1. Indeks kiełkujących zarodników Blumeriella jaapii na podłożu PDA z dodatkiem fungicydu (2012 r.)

Table1. Index of germinating spores of Blumeriella jaapii on the PDA medium with the addition of fungicide (2012)

\begin{tabular}{|c|c|c|c|c|c|c|c|c|}
\hline \multirow{3}{*}{$\begin{array}{l}\text { Lokalizacja } \\
\text { Location }\end{array}$} & \multirow{3}{*}{$\begin{array}{l}\text { Województwo } \\
\text { Province }\end{array}$} & \multicolumn{7}{|c|}{$\begin{array}{l}\text { Indeks kiełkujących zarodników (IKZ) } \\
\text { Index of germinating spores [\%] }\end{array}$} \\
\hline & & \multicolumn{4}{|c|}{ tiofanat metylu - thiophanate-methyl } & \multicolumn{3}{|c|}{ dodyna-dodine } \\
\hline & & $1 \mathrm{ppm}$ & $10 \mathrm{ppm}$ & 50 ppm* & $100 \mathrm{ppm}$ & $1 \mathrm{ppm}$ & $10 \mathrm{ppm}$ & $100 \mathrm{ppm}$ \\
\hline Julków & łódzkie & 101,5 & 21,1 & - & 21,7 & 18,9 & 0 & 0 \\
\hline Józefów & lódzkie & 78,0 & 12,9 & - & 0 & 0 & 0 & 0 \\
\hline Dąbrowice & lódzkie & 99,6 & 98,3 & - & 0 & 35,1 & 0 & 0 \\
\hline Dębowa Góra & łódzkie & 7,0 & 0 & - & 0 & 0 & 0 & 0 \\
\hline Jadwigów & mazowieckie & 97,4 & 95,8 & - & 33,0 & 18,2 & 0 & 0 \\
\hline Zalesie gmina Skierniewice & tódzkie & 101,2 & 100,0 & - & 6,5 & 24,4 & 0 & 0 \\
\hline Turowa Wola 1 & łódzkie & 102,3 & 96,1 & - & 0 & 0 & 0 & 0 \\
\hline Wilcze Średnie 1 & mazowieckie & 105,1 & 96,2 & - & 0 & 0 & 0 & 0 \\
\hline Ziemięcin & mazowieckie & 104,9 & 100,0 & - & 0 & 58,6 & 0 & 0 \\
\hline Zalesie gmina Grójec 1 & mazowieckie & 104,3 & 100,0 & - & 0 & 49,2 & 0 & 0 \\
\hline Pękoszew 1 & lódzkie & 99,4 & 25,6 & - & 0 & 28,6 & 0 & 0 \\
\hline
\end{tabular}

*stężenie 50 ppm w roku 2012 nie było badane - the concentration of 50 ppm in 2012 has not been studied 
Tabela 2. Indeks kiełkujących zarodników Blumeriella jaapii na podłożu PDA z dodatkiem fungicydu (2013 r.)

Table 2. Index of germinating spores of Blumeriella jaapii on the PDA medium with the addition of fungicide (2013)

\begin{tabular}{l|c|c|c|c|c}
\hline \multirow{2}{*}{$\begin{array}{c}\text { Lokalizacja } \\
\text { Location }\end{array}$} & \multirow{2}{*}{$\begin{array}{c}\text { Województwo } \\
\text { Province }\end{array}$} & \multicolumn{4}{c}{$\begin{array}{c}\text { Indeks kiełkujących zarodników (IKZ) } \\
\text { Index of germinating spores [\%] }\end{array}$} \\
\cline { 3 - 6 } & & \multicolumn{2}{c}{ tiofanat metylu - thiophanate-methyl } & dodyna - dodine \\
\cline { 3 - 6 } & & $10 \mathrm{ppm}$ & $50 \mathrm{ppm}$ & $100 \mathrm{ppm}$ & $1 \mathrm{ppm}$ \\
\hline Kacprówka & mazowieckie & 75,4 & 36,8 & 25,7 & 49,7 \\
\hline Błażejowice gmina Biała Rawska & lódzkie & 74,3 & 11,8 & 3,3 & 15,7 \\
\hline Grzymkowice 1 & lódzkie & 46,0 & 0,6 & 3,3 & 43,7 \\
\hline Turowa Wola 2 & lódzkie & 86,6 & 54,3 & 44,2 & 3,2 \\
\hline Jakubów & mazowieckie & 77,0 & 55,3 & 17,5 & 0,8 \\
\hline Lindów & mazowieckie & 76,2 & 71,5 & 35,7 & 0,4 \\
\hline Byki & lódzkie & 91,6 & 72,6 & 44,8 & 0,4 \\
\hline Nowy Dwór (sad ekologiczny) & lódzkie & 73,2 & 44,5 & 11,2 & 0 \\
\hline Huta Zawadzka & lódzkie & 67,0 & 25,2 & 14,1 & 0,2 \\
\hline Nowy Dwór & lódzkie & 99,4 & 52,2 & 54,9 & 0 \\
\hline Pękoszew 2 & lódzkie & 100,0 & 48,2 & 0,6 & 0,2 \\
\hline Skierniewice & lódzkie & 47,3 & 20,8 & 1,0 & 0,2 \\
\hline Zalesie gmina Grójec 2 & lódzkie & 53,5 & 53,5 & 4,5 & 0,2 \\
\hline
\end{tabular}

Tabela 3. Indeks kiełkujących zarodników Blumeriella jaapii na podłożu PDA z dodatkiem fungicydu (2014 r.)

Table 3. Index of germinating spores of Blumeriella jaapii on the PDA medium with the addition of fungicide (2014)

\begin{tabular}{|c|c|c|c|c|c|}
\hline \multirow{3}{*}{$\begin{array}{l}\text { Lokalizacja } \\
\text { Location }\end{array}$} & \multirow{3}{*}{$\begin{array}{c}\text { Województwo } \\
\text { Province }\end{array}$} & \multicolumn{4}{|c|}{$\begin{array}{l}\text { Indeks kiełkujących zarodników (IKZ) } \\
\text { Index of germinating spores [\%] }\end{array}$} \\
\hline & & \multicolumn{3}{|c|}{ tiofanat metylu - thiophanate-methyl } & \multirow{2}{*}{$\frac{\text { dodyna }- \text { dodin }}{1 \mathrm{ppm}}$} \\
\hline & & $10 \mathrm{ppm}$ & $50 \mathrm{ppm}$ & $100 \mathrm{ppm}$ & \\
\hline Grzymkowice 2 & łódzkie & 20,1 & 8,1 & 1,2 & 39,3 \\
\hline Grzymkowice 3 & łódzkie & 35,3 & 7,7 & 0,5 & 72,6 \\
\hline Narty 1 & łódzkie & 71,6 & 62,2 & 6,0 & 75,6 \\
\hline Narty 2 & łódzkie & 47,7 & 10,0 & 1,6 & 83,0 \\
\hline Józefatów & łódzkie & 80,0 & 57,8 & 2,2 & 88,9 \\
\hline
\end{tabular}

Tabela 4. Indeks kiełkujących zarodników Blumeriella jaapii na podłożu PDA z dodatkiem fungicydu (2015 r.)

Table 4. Index of germinating spores of Blumeriella jaapii on the PDA medium with the addition of fungicide (2015)

\begin{tabular}{|c|c|c|c|c|c|}
\hline \multirow{3}{*}{$\begin{array}{l}\text { Lokalizacja } \\
\text { Location }\end{array}$} & \multirow{3}{*}{$\begin{array}{l}\text { Województwo } \\
\text { Province }\end{array}$} & \multicolumn{4}{|c|}{$\begin{array}{l}\text { Indeks kiełkujących zarodników (IKZ) } \\
\text { Index of germinating spores [\%] }\end{array}$} \\
\hline & & \multicolumn{3}{|c|}{ tiofanat metylu - thiophanate-methyl } & \multirow{2}{*}{$\frac{\text { dodyna }- \text { dodine }}{1 \mathrm{ppm}}$} \\
\hline & & $10 \mathrm{ppm}$ & $50 \mathrm{ppm}$ & $100 \mathrm{ppm}$ & \\
\hline Wierzchowina & mazowieckie & 3,2 & 1,1 & 0 & 3,2 \\
\hline Wilcze Średnie 2 & mazowieckie & 0 & 0 & 0 & 0 \\
\hline Goszczyn 1 & mazowieckie & 1,1 & 0 & 0 & 0 \\
\hline Goszczyn 2 & mazowieckie & 0 & 0 & 0 & 1,0 \\
\hline
\end{tabular}

W Polsce słabszą skuteczność fungicydów dodynowych i benzimidazolowych w zwalczaniu drobnej plamistości liści drzew pestkowych na wiśniach zaobserwowano pod koniec lat 80. ubiegłego stulecia (Bielenin i wsp. 1991). Ze względu na występowanie form grzyba $B$. jaapii odpornych na dodynę i benzimidazole, w wielu krajach związki te wycofano z programów zwalczania tej choroby (Ma i Michailides 2005; Holb i wsp. 2010). W Polsce wymienione grupy fungicydów są wciąż powszechnie używane, ale wyniki przedstawionych badań wskazują, że w niektórych sadach wiśniowych występują już formy B. jaapii odporne na dodynę i tiofanat metylu - jedyną obecnie zarejestrowaną w uprawach sadowniczych substancję z grupy benzimidazoli.

Uzyskane wyniki będą podstawą do wprowadzania odpowiednich zaleceń antyodpornościowych w opraco- 
wywanych programach zwalczania drobnej plamistości liści drzew pestkowych. Zalecenia te dotyczą przede wszystkim ograniczenia liczby opryskiwań fungicydami dodynowymi do 2 razy, a preparatami zawierającymi tiofanat metylu do jednego zabiegu w sezonie. Ważne jest także przemienne stosowanie fungicydów o różnym mechanizmie działania oraz przestrzeganie zalecanych dawek i terminów stosowania z uwzględnieniem warunków atmosferycznych, tempa rozwoju drzew i zagrożenia chorobowego.

\section{Wnioski / Conclusions}

1. Zastosowana metoda oznaczania odporności grzyba B. jaapii na pożywce mikrobiologicznej z dodatkiem fungicydów w określonych stężeniach, pozwala na przeprowadzenie wstępnej oceny występowania form odpornych oraz selekcję izolatów do molekularnych badań mechanizmów odporności.

2. Przeprowadzone badania wykazały po raz pierwszy w Polsce, występowanie w sadach wiśniowych form odpornych grzyba $B$. jaapii na fungicydy dodynowe i tiofanat metylu. Poznanie skali tego zjawiska na terenie całego kraju wymaga jednak dalszych badań w większej liczbie sadów.

3. Monitoring występowania form odpornych B. jaapii na stosowane środki ochrony roślin jest ważnym elementem opracowania optymalnego programu ochrony wiśni przed drobną plamistością liści drzew pestkowych.

\section{Literatura / References}

Bielenin A., Bachnacki R., Cimanowski J., Karczewski J., Olszak M., Rechnio H. 1991. Effectiveness of several new fungicides in the control of cherry leaf spot. Fruit Science Reports 18 (3): 133-137.

Broniarek-Niemiec A., Bielenin A. 2005. Monitoring odporności Venturia inaequalis na fungicydy strobilurynowe i dodynowe. [Monitoring of Venturia inaequalis resistance to strobiluryn and dodine fungicides]. Zeszyty Naukowe Instytutu Sadownictwa i Kwiaciarstwa 13: 143-150.

Broniarek-Niemiec A., Bielenin A. 2008. Aktualne zagrożenia sadów wiśniowych chorobami powodowanymi przez grzyby i możliwości ich zwalczania. [Importance and control of fungal diseases in sour cherry orchards]. Progress in Plant Protection/Postępy w Ochronie Roślin 48 (2): 445-449.

Broniarek-Niemiec A., Meszka B., Bielenin A. 2012. Występowanie form odpornych grzyba Venturia inaequalis na fungicydy w latach 2008-2011. 55. Ogólnopolska Konferencja Ochrony Roślin Sadowniczych. Centrum Kongresowe, Ossa koło Białej Rawskiej, 15-16 lutego 2012: 82-84.

Broniarek-Niemiec A., Poniatowska A., Michalecka M. 2013. Ochrona drzew pestkowych przed chorobami - aktualne problemy i zalecenia. 56. Ogólnopolska Konferencja Ochrony Roślin Sadowniczych. Centrum Kongresowe, Ossa koło Białej Rawskiej, 14-15 lutego 2013: 104-107.

Diaz R., Zas R., Fernandez-Lopez J. 2007. Genetic variation of Prunus avium in susceptibility to cherry leaf spot (Blumeriella jaapii) in spatially heterogeneous infected seed orchards. Annals of Forest Science 64: 21-30.

Grzyb Z.S., Piotrowski W., Sas-Paszt L. 2012. Effect of biofertilizers and soil conditioners used in an ecological nursery on the degree of infection by leaf spot of sour cherry maiden trees (Blumeriella jaapii Rehm.). Journal of Research and Applications in Agricultural Engineering 57 (3): 153-156.

Holb I.J., Lakatos P., Abonyi F. 2010. Some aspects of disease management of cherry leaf spot (Blumeriella jaapii) with special reference to pesticide use. International Journal of Horticultural Science 16 (1): 45-49.

Holb I.J., Vasileiadis V.P., Vamos A. 2014. Effect of sanitation treatment and cultivar on saprophytic development of Blumeriella jaapii in integrated and organic sour cherry orchards. Australasian Plant Pathology 43 (4): 439-446.

Jones A.L. 1981. Fungicide resistance past experience with benomyl and dodine and future concerns with sterol inhibitors. Plant Disease 65 (12): 990-992.

Jones A.L., Ehret G.R. 1980. Resistance of Coccomyces hiemalis to benzimidazole fungicides. Plant Disease 64: 767-769.

Kryczyński S. 2002. Podstawy fitopatologii. Fundacja Rozwój SGGW, Warszawa, 216 ss.

Köller W., Wilcox W.F. 2001. Evidence for the predisposition of fungicide-resistant isolates of Venturia inaequalis to a preferential selection for resistance to other fungicides. Phytopathology 91 (8): 776-781.

Ma Z., Michailides T.J. 2005. Advances in understanding molecular mechanisms of fungicide resistances and molecular detection of resistant genotypes in phytopathogenic fungi. Crop Protection 24 (10): 853-863.

McManus P.S., Proffer T.J., Berardi R., Gruber B.R., Nugent J.E., Ehret G.R., Ma Z., Sundin G.W. 2007. Integration of copper-based and reduced-risk fungicides for control of Blumeriella jaapii on sour cherry. Plant Disease 91 (3): 294-300.

Meszka B., Broniarek-Niemiec A., Bielenin A. 2011. Problem odporności Venturia inaequalis na fungicydy w polskich sadach jabłoniowych. 54. Ogólnopolska Konferencja Ochrony Roślin Sadowniczych. Centrum Kongresowe, Ossa koło Białej Rawskiej, 23-24 lutego 2011: 60-62.

Nowacka H. 1991. Stability of resistance to benzimidazole fungicides in Venturia inaequalis (Cke) Aderh. Fruit Science Reports 18 (3): $143-146$.

Nowacka H., Karolczak W., Millikan D.F. 1977. Tolerance of apple fungus to the bezimidazole fungicides in Poland. The Plant Disease Reporter 61 (5): 346-350.

Nowaczyk K., Obrępalska-Stęplowska A. 2006. Wybrane mechanizmy nabywania odporności organizmów na środki ochrony roślin. Postępy Biologii Komórki 33 (1): 137-158.

Proffer T.J., Berardi R., Ma Z., Nugent J.E., Ehret G.R., McManus P.S., Jones A.L., Sundin G.W. 2006. Occurrence, distribution, and polymerase chain reaction-based detection of resistance to sterol demethylation inhibitor fungicides in populations of Blumeriella jaapii in Michigan. Phytopathology 96 (7): 709-717.

Program Ochrony Roślin Sadowniczych. 2015. Redakcja Pracownicy Instytutu Ogrodnictwa w Skierniewicach. Hortpress, Warszawa, 224 ss. 